\title{
Pengaruh Variasi Lip Thickness pada Nozzle Terpancung terhadap Karakteristik Api Pembakaran Difusi Concentric Jet Flow
}

\author{
Elka Faizal ${ }^{1}$, Agung Sugeng Widodo², Mega Nur Sasongko ${ }^{3}$ \\ 1, 2, 3 Teknik Mesin Universitas Brawijaya Indonesia, Jl. MT. Haryono, 167 - Malang 65145 \\ E-mail address: elka6388@gmail.com
}

\begin{abstract}
Nozzle shape greatly influence turbulence between the fuel, air and formation of flow recirculation zone to produce a homogeneous mixing and get a near-perfect combustion. The recirculation zone is area that caused by flow rate breakdown, causing vortex and backflow around the end of nozzle. This backflow that hold up while lowering the flame so the flow rate of fuel and air mixture maintained lower or equal with flame speed. This study used variation of lip thickness of truncated nozzle $0,4,8,12$, and 16 $\mathrm{mm}$. To obtain flame stability, fuel velocity and air velocity were variated. Thermocouples were used to measure flame temperature and its distribution. The results showed that stability of concentric jet diffusion flame flow increased with narrow lip thickness on a truncated nozzle. The wider stability area obtained in $4 \mathrm{~mm}$ lip thickness. In addition, temperature on diffusion flames concentric jet flow also more evenly distributed evenly with size of the nozzle lip thickness. The highest temperature and temperature distribution in the horizontal direction were occured in in the nozzle with lip thickness of $0 \mathrm{~mm}$. A shadowgrapgh visualization was also used to identify phenomena of the nozzle exit flow.
\end{abstract}

Keywords : diffussion flame, lip thickness, concentric jet flow, recirculation zone

\section{PENDAHULUAN}

Proses pembakaran merupakan proses yang sangat penting dalam memanfaatkan energi kimiawi bahan bakar yang digunakan untuk memenuhi kebutuhan energi manusia. Salah satu jenis pembakaran yang umum digunakan dalam bidang industri adalah pembakaran difusi. Pada pembakaran difusi bahan bakar yang dialirkan melalui saluran burner dibuat terpisah dari saluran udara, sehingga pencampuran bahan bakar dan udara tidak terjadi secara mekanik sebelum terjadinya proses pembakaran melainkan bercampur sendiri secara alami dengan proses difusi sesaat sebelum proses pembakaran. Salah satu keuntungan digunakannya pembakaran difusi pada bidang industri adalah dari sisi keamanan, yaitu tidak adanya bahaya flash back. Tetapi di sisi lain, pembakaran difusi memiliki kelemahan yaitu sulitnya mendapatkan komposisi campuran yang homogen antara bahan bakar dan udara. Oleh sebab itu, salah satu upaya untuk mengatasi permasalahan tersebut adalah dengan cara mendesain sistem pembakaran difusi yang optimal, sehingga didapatkan suatu desain burner yang efektif dan efisien.

Salah satu faktor yang mempengaruhi karakteristik pembakaran api difusi adalah geometri burner. Geometri burner sangat berpengaruh dalam proses pencampuran antara bahan bakar dan udara, sehingga mempengaruhi karakteristik pembakaran. Pada proses pencampuran antara bahan bakar dan udara, kehadiran vorteks-vorteks akibat struktur geometri burner berperan penting sebagai pengaduk aliran. Dinamika vorteks hadir pada struktur aliran api non-premix yang bertujuan untuk menstabilkan proses pembakaran[1]. Daerah kestabilan api difusi dapat diperluas dengan pemasangan swirling vanes[2]. Kestabilan api pada umumnya menjelaskan batas operasional dari sistem pembakaran. Ada dua kondisi aliran kritis yang berhubungan dengan kestabilan api, yaitu lift off dan blow off. Oleh karena kondisi kritis batas kestabilan tersebut sangat tergantung pada kondisi geometris burnemya, maka pada penelitian ini digunakan nozzle dengan variasi lip thickness terpancung pada tipe burner concentric jet flow. Lip thickness burner berpengaruh terhadap kestabilan api non-premixed akibat perubahan zona resirkulasi aliran[3]. Aliran resirkulasi yang merupakan faktor penting dalam kestabilan api dengan jalan pengadukan bahan bakar baik di belakang halangan maupun untuk proses pencampurannya[4]. Zona resirkulasi adalah daerah dimana terjadi pemecahan laju aliran yang menimbulkan pusaran (vortex) dan aliran balik di sekitar ujung nozzle. Dengan penggunaan variasi lip thickness nozzle terpancung pada penelitian ini, diharapkan akan terjadi pemecahan laju aliran sehingga terbentuk zona resirkulasi yang akan menyempurnakan pembakaran. Hal ini diindikasikan dengan kemudahan terbentuknya lift off dan blow off sebagai indikator kestabilan api difusi.

Pengaruh kecepatan bahan bakar pada concentric jet flow terhadap kondisi lift off diteliti untuk laju aliran udara yang dibuat konstan dengan laju aliran bahan bakar yang bervariasi. Tinggi pangkal nyala meningkat secara linier terhadap kecepatan aliran gas yang keluar dari nozzle[5]. Dengan semakin kecil ketebalan lip thickness pada nozzle terpancung akan mempermudah terciptanya pemecahan aliran yang berguna dalam menjaga kecepatan aliran reaktan agar lebih rendah atau sama dengan kecepatan nyala serta berperan dalam proses pengadukan bahan bakar dengan udara akibat terbentuknya zona resirkulasi, sehingga memperkecil peluang terjadinya lift off dan blow off atau dengan 
kata lain terjadi peningkatan kestabilan api difusi.

Kestabilan api difusi memiliki hubungan erat dengan temperatur pembakaran. Semakin tinggi kestabilan api difusi maka temperatur pembakaran juga semakin tinggi. Salah satu faktor penting dalam peningkatan temperatur pembakaran adalah proses pencampuran antara bahan bakar dengan udara. Pada proses pencampuran reaktan salah satu faktor yang mempengaruhi adalah adanya turbulensi aliran yang berguna dalam proses mixing reaktan. Turbulensi aliran fluida menyebabkan pergeseran batas kritis kestabilan api difusi dan meningkatkan distribusi temperatur nyala sehingga menghasilkan pembakaran yang sempurna[6]. Distribusi temperatur mulai dari burner tip hingga flame tip sangat penting diketahui. Hal ini berguna dalam menentukan seberapa baik pencampuran antara bahan bakar dengan udara yang dapat diketahui dari seberapa besar temperatur nyala api tersebut. Distribusi temperatur api difusi semakin merata ke arah horisontal seiring dengan peningkatan sudut luar maupun sudut dalam nozzle akibat terbentuknya zona resirkulasi aliran[7]. Zona resirkulasi berperan dalam meningkatkan kestabilan api difusi dengan cara menjaga kecepatan aliran reaktan lebih rendah atau sama dengan kecepatan nyala, serta berperan dalam proses pengadukan bahan bakar dengan udara. Pada penelitian ini semakin kecil luasan lip thickness pada nozzle terpancung mempermudah terjadinya proses pengadukan reaktan pada zona resirkulasi yang menyebabkan campuran bahan bakar semakin homogen sebelum terbakar, sehingga pembakaran semakin sempurna yang diindikasikan dengan meningkatnya termperatur pembakaran. Selain itu untuk menunjang dan mempertegas hasil yang didapat dari penelitian ini, maka diperlukan suatu metode untuk menvisualisasikan struktur aliran tersebut. Oleh karena pola aliran sangat dipengaruhi oleh densitas aliran, maka digunakan teknik visualisasi shadowgraph. Dengan visualisasi shadowgraph, maka didapatkan gambaran nyata adanya perbedaan densitas aliran, sehingga struktur aliran pada proses pencampuran antara bahan bakar dan udara dapat terlihat secara jelas.

\section{METODOLOGI PENELITIAN}

Peneltian ini dilakukan secara eksperimental (experimental research) dengan variasi lip thickness nozzle terpancung : $0 \mathrm{~mm}, 4 \mathrm{~mm}, 8 \mathrm{~mm}, 12 \mathrm{~mm}$, dan $16 \mathrm{~mm}$, dimana data yang diambil adalah kestabilan nyala dan temperatur api difusi concentric jet flow. Skema penelitian dan bentuk nozzle ditunjukkan pada Gambar 1 dan 2.

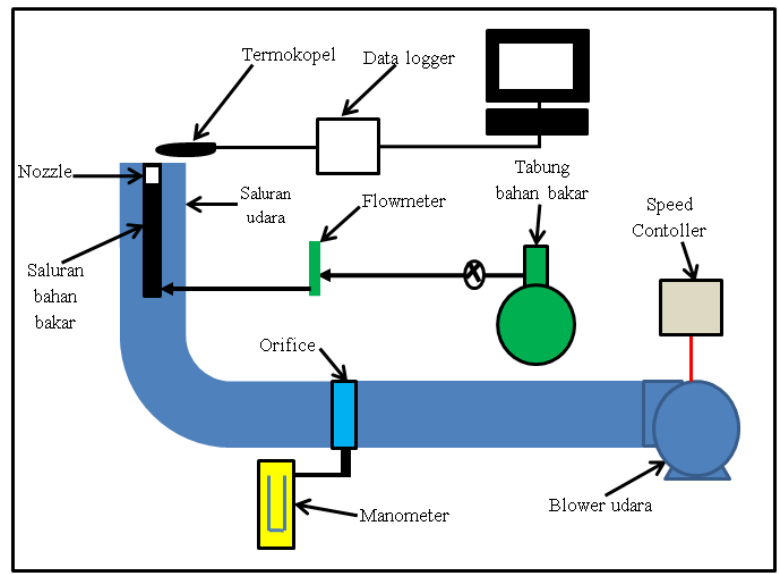

Gambar 1. Instalasi Penelitian

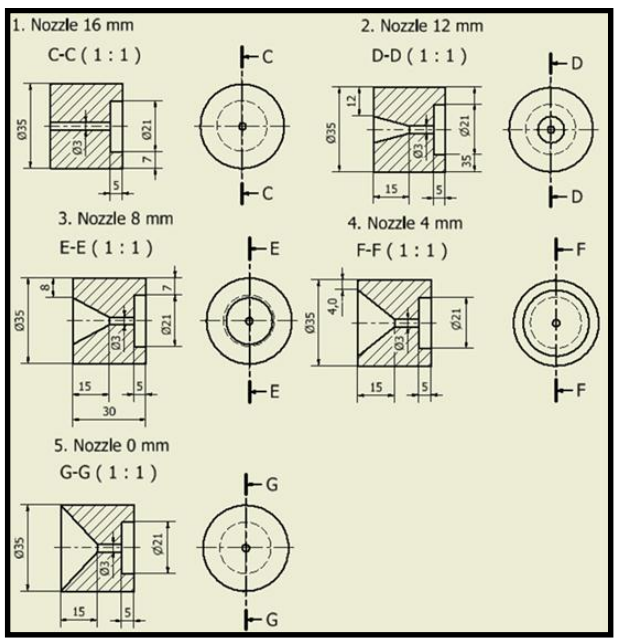

Gambar 2. Nozzle terpancung dengan variasi lip thickness 


\section{Pengujian Kestabilan Api Difusi}

Sebelum melakukan pengujian perlu dilakukan persiapan peralatan-peralatan serta memastikan bahwa peralatan dapat bekerja dengan baik dan aman. Selain itu perlu dilakukan kalibrasi peralatan ukur yang akan digunakan, seperti alat ukur laju aliran bahan bakar dan udara maupun alat ukur temperatur untuk menjamin ketepatan hasil pengukuran.

Pengujian kestabilan api diawali dengan menyalakan blower udara dan mengukur kecepatan udara yang keluar dari burner menggunakan anemometer. Pada penelitian ini kecepatan awal yang digunakan sebesar $1 \mathrm{~m} / \mathrm{s}$. Agar tepat perlu dilakukan pengaturan kecepatan blower yang disesuaikan dengan pembacaan pada anemometer. Selanjutnya memasang nozzle dengan lip thickness terpancung 16 $\mathrm{mm}$ dan dilanjutkan dengan membuka katup bahan bakar serta menyalakan api. Untuk mengatur supply bahan bakar yang akan digunakan dalam pengujian dilakukan dengan flowmeter. Debit bahan bakar yang digunakan akan dikonversikan menjadi kecepatan bahan bakar. Kemudian pengujian dilanjutkan dengan mengatur aliran bahan bakar pada kondisi api stabil yaitu pada debit $3 \mathrm{l} / \mathrm{min}$ dan $5 \mathrm{l} / \mathrm{min}$ dengan tetap menjaga beda ketinggian pada manometer $2 \mathrm{~mm}$. Mengambil gambar dari api yang terbentuk dengan menggunakan kamera digital Nikon D3200. Selanjutnya memperbesar aliran bahan bakar hingga mencapai kondisi lift off dan dilanjutkan dengan blow off serta mencatat debit bahan bakar ketika terjadi lift off dan blow off.

Tahap pengujian kestabilan api difusi concentric jet flow dengan nozzle $16 \mathrm{~mm}$ pada $\Delta \mathrm{h}=2 \mathrm{~mm}$ sudah selesai dilakukan, tahap selanjutnya adalah tetap menggunakan nozzle $16 \mathrm{~mm}$ tetapi menaikkan kecepatan udara, sehingga beda tekanan yang terbaca pada manometer menjadi $6 \mathrm{~mm}$ kemudian mengulangi langkah pengujian seperti sebelumnya. Pengujian ini diulangi dengan $\Delta \mathrm{h}$ manometer 10, 16, dan $24 \mathrm{~mm}$.

Setelah pengujian kestabilan api difusi concentric jet flow menggunakan nozzle terpancung dengan lip thickness $16 \mathrm{~mm}$ selesai dilakukan, maka pengujian tahap selanjutnya adalah mengganti nozzle terpancung dengan lip thickness $16 \mathrm{~mm}$ dengan nozzle $12 \mathrm{~mm}, 8 \mathrm{~mm}, 4 \mathrm{~mm}$, dan $0 \mathrm{~mm}$, dengan mengulangi langkah-langkah yang telah dilakukan sebelumnya kemudian mengolah data-data yang didapat dan melakukan analisa serta mengambil kesimpulan dari penelitian yang telah dilakukan.

\section{Pengujian Distribusi Temperatur}

Pengujian distribusi temperatur nyala api difusi concentric jet flow dengan variasi lip thickness pada nozzle terpancung dilakukan terpisah dengan pengujian kestabilan api disebabkan karena dikhawatirkan pemasangan termokopel dapat mengganggu struktur aliran api. Tahap awal pengujian distribusi temperatur adalah menyalakan api dan mengatur kecepatan udara pada kondisi api stabil. Kemudian dilanjutkan dengan memasang termokopel pada titik-titik yang telah ditentukan seperti pada Gambar 3.

Titik tinjau yang digunakan tiap $10 \mathrm{~mm}$ dalam arah horizontal dan jarak jarak 25, 50, 100, $200 \mathrm{~mm}$ pada arah vertikal. Termokopel dipasang pada data logger yang terhubung dengan komputer dan digunakan untuk mengambil data temperatur api difusi.

Proses pengujian dilanjutkan dengan mengganti nozzle terpancung dengan nozzle yang berbeda ketebalannya kemudian mengulang proses sebelumnya. Setelah mendapatkan data distribusi temperatur api, data kemudian diolah dan dilakukan analisa mengenai pengaruh variasi lip thickness pada nozzle terpancung terhadap temperatur nyala api pembakaran difusi concentric jet flow.

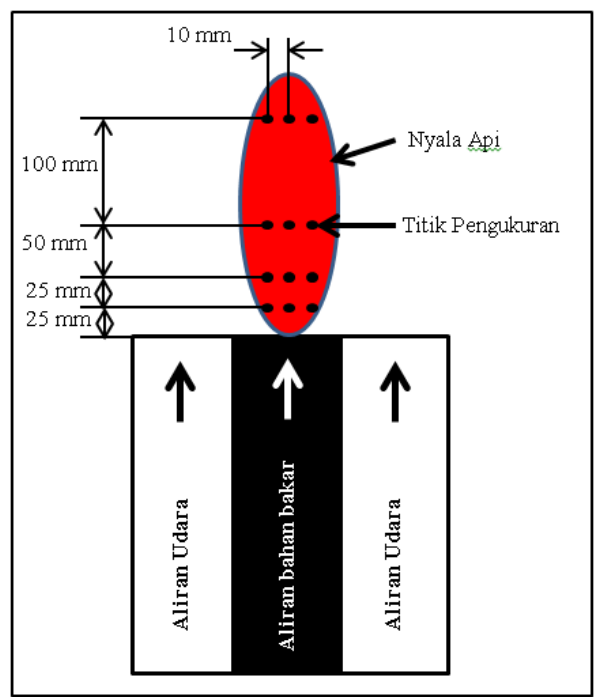

Gambar 3. Titik Tinjau Temperatur Api Difusi

\section{Pengujian Visualisasi Shadowgraph}

Pengujian ini dilakukan untuk mendapatkan gambaran nyata tentang pola aliran pada nyala api difusi concentric jet flow yang digunakan untuk mendukung dan mempertegas hasil yang didapat dari penelitian yang telah dilakukan Pengujian diawali dengan menyusun peralatan uji seperti pada Gambar 4.

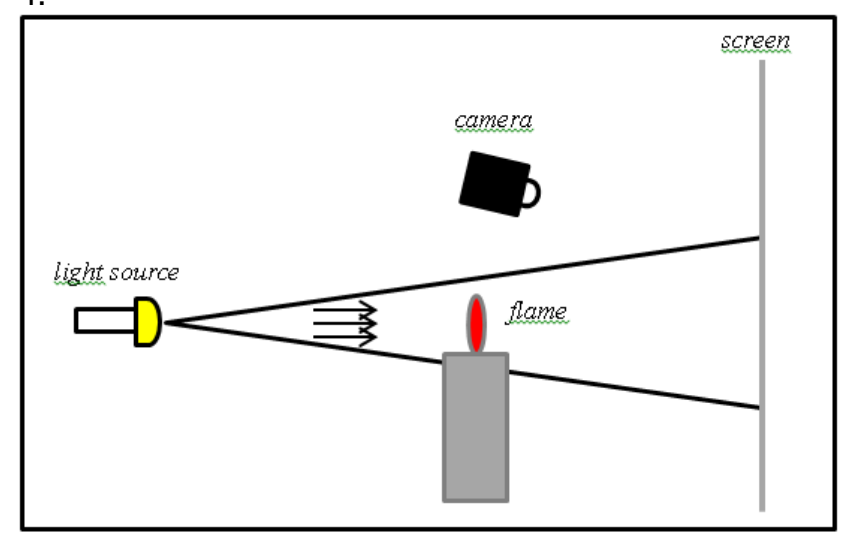

Gambar 4. Skema Visualisasi Shadowgraph

Layar putih dengan lebar $1.5 \mathrm{~m}$ dan tinggi $2 \mathrm{~m}$ dipasang tepat di belakang burner. Selain itu lampu 
500 Watt dipasang dan diatur sudut serta fokus pencahayaannya agar nanti dapat menciptakan bayangan dari api yang terbentuk pada layar. Tahap selanjutnya menyalakan api dan mengatur kecepatan udara serta debit bahan bakar pada kondisi api stabil dan dikondisikan seperti pada pengujian distribusi temperatur api agar hasil yang diperoleh dapat saling dihubungkan. Kemudian dilanjutkan dengan mengambil gambar dari bayangan api yang terbentuk pada layar menggunakan kamera. Proses pengujian ini diulang dengan menggunakan nozzle uji yang berbeda, sehingga didapatkan gambar bayangan api dari masing-masing nozzle. Setelah itu mengolah data dan melakukan analisa mengenai pengaruh variasi lip thickness pada nozzle terpancung terhadap karakteristik pencampuran aliran bahan bakar dan udara dari nyala api pembakaran difusi concentric jet flow serta menarik kesimpulan dari penelitian yang dilakukan.

\section{HASIL DAN PEMBAHASAN Kestabilan Api Difusi}

Lift off terjadi akibat ketidak seimbangan antara kecepatan aliran bahan bakar pada pangkal api dan kecepatan penyalaan dalam proses pencampuran antara aliran jet bahan bakar dengan udara pengoksidasi. Pada variasi lip thickness pada nozzle terpancung $16 \mathrm{~mm}, 12 \mathrm{~mm}$, dan $8 \mathrm{~mm}$, semakin besar aliran udara maka lift off memiliki kecenderungan semakin cepat terjadi. Hal ini terjadi dikarenakan semakin cepat aliran udara, maka proses pencampuran antara bahan bakar dan udara juga semakin cepat yang menyebabkan waktu yang tersedia untuk melakukan reaksi (characteristic chemical time) juga semakin kecil, sehingga titik pangkal nyala api semakin mudah terangkat menjauhi ujung nozzle.

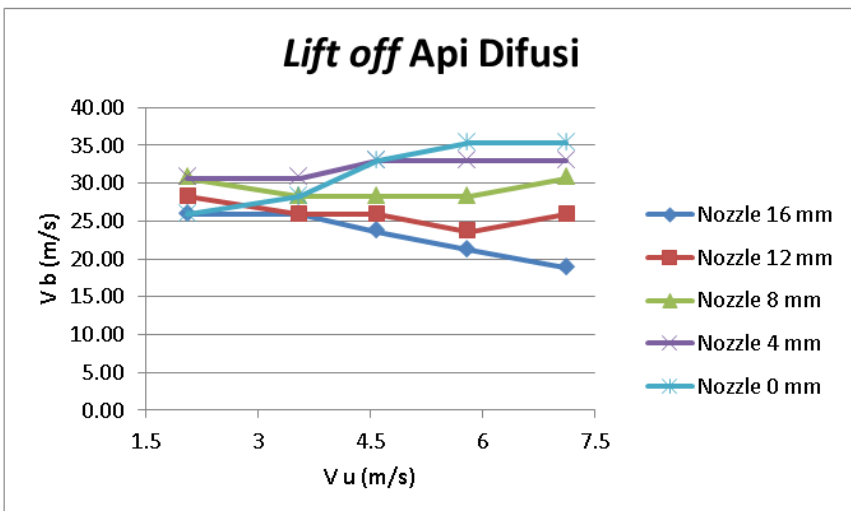

Gambar 5. Diagram gabungan lift off dengan variasi lip thickness pada nozzle terpancung.

Gambar 5 menunjukkan bahwa dengan variasi lip thickness pada nozzle terpancung membuat luasan daerah kestabilan api berubah. Semakin kecil lip thickness yang digunakan, maka luasan daerah kestabilan memiliki kecenderungan semakin bertambah. Hal ini terjadi karena dengan semakin kecilnya lip thickness, intensitas turbulensi dan zona resirkulasi yang terbentuk juga semakin besar, menyebabkan pencampuran udara dan bahan bakar menjadi semakin homogen dan pembakaran semakin mendekati sempurna, sehingga memperlambat proses terjadinya lift off.

Disisi lain terlihat jelas pengaruh zona resirkulasi aliran dalam menahan nyala api dan menyempurnakan proses pembakaran. Pada variasi lip thickness nozzle terpancung $4 \mathrm{~mm}$ dan $0 \mathrm{~mm}$ semakin tinggi kecepatan udara membuat kestabilan api justru semakin meningkat. Hal ini terjadi akibat adanya zona resirkulasi aliran yang menyebabkan timbulnya pusaran dan aliran balik di sekitar permukaan nozzle. Aliran balik inilah yang menghambat sekaligus menekan nyala api sehingga mencegah terjadinya lift off. Selain itu zona resirkulasi aliran sangat berguna dalam proses pengadukan reaktan, menyebabkan pencampuran antara bahan bakar dan udara menjadi semakin homogen sehingga membuat reaksi pembakaran mendekati sempurna. Zona resirkulasi aliran juga berperan dalam memecah laju aliran sehingga kecepatan aliran bahan bakar dan udara dapat terjaga lebih rendah atau sama dengan kecepatan nyala.

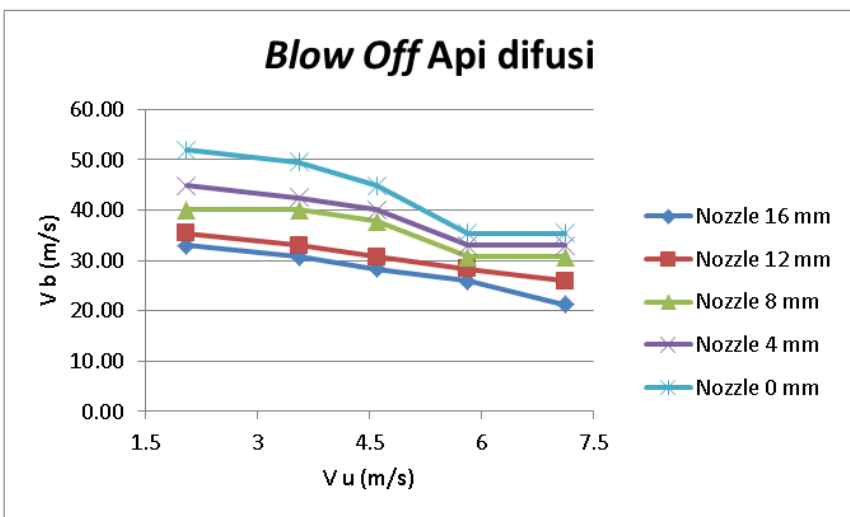

Gambar 6. Diagram gabungan blow off dengan variasi lip thickness pada nozzle terpancung.

Gambar 6 menunjukkan profil dari tiap-tiap diagram cenderung sama, yakni mempunyai batas blow off yang relatif tinggi pada kecepatan udara yang rendah dan menurun seiring dengan bertambahnya laju aliran udara. Hal ini terjadi karena semakin cepat aliran udara, maka proses pencampuran antara bahan bakar dan udara juga semakin cepat, akibatnya Damkohler number ( $D a)$ menjadi semakin kecil, yang berarti waktu yang tersedia untuk melakukan reaksi (characteristic chemical time) tidak mencukupi dibandingkan dengan waktu mengalirnya reaktan (characteristic flow time). Sehingga api mengalami blow off meskipun campuran antara bahan bakar dan udara masih dalam batas mampu nyala. Selain itu terlihat bahwa bahwa dengan variasi lip thickness pada nozzle terpancung membuat batas blow off api berubah. Semakin kecil lip thickness yang digunakan, maka batas blow off api cenderung semakin meningkat. Hal ini terjadi karena dengan semakin kecilnya lip thickness, intensitas turbulensi dan zona 
resirkulasi yang terbentuk juga semakin besar, sehingga menyebabkan pencampuran udara dan bahan bakar menjadi semakin homogen dan pembakaran semakin mendekati sempurna. Selain itu pengadukan pada proses pencampuran udara bahan bakar akan menyebabkan pemanasan awal pada reaktan, dimana hal ini juga berperan dalam menyempurnakan reaksi pembakaran.

\section{Distribusi Temperatur Api Difusi}

Untuk mengetahui distribusi temperatur api difusi, maka perlu dibuat suatu grafik distribusi temperatur mulai dari burner tip hingga flame tip. Hal ini berguna dalam menentukan seberapa baik pencampuran antara bahan bakar dengan udara yang dapat diketahui dari seberapa besar temperatur nyala api tersebut. Grafik distribusi temperatur ini menunjukkan nilai rata-rata temperatur pada tiap-tiap titik tinjau dengan cara membandingkan temperatur di jarak horizontal pada jarak vertikal yang sama dengan variasi lip thickness pada nozzle terpancung, sehingga dapat diketahui perbedaan distribusi temperatur pada penggunaan masing-masing nozzle pengujian. Pada pengujian ini titik tinjau pengukuran pada arah vertikal adalah 25, 50, 100, dan $200 \mathrm{~mm}$ dari ujung nozzle, sedangkan pada arah horizontal adalah -10. 0, dan $10 \mathrm{~mm}$ dari sumbu nozzle.

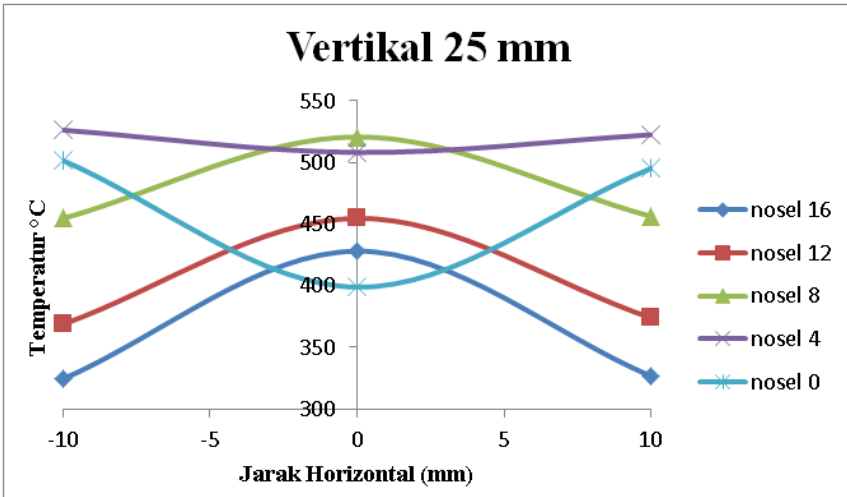

Gambar 7. Grafik distribusi temperatur api pada titik tinjau vertikal $25 \mathrm{~mm}$ dengan variasi lip thickness pada nozzle terpancung

Gambar 7 menunjukkan distribusi temperatur pada jarak vertikal terkecil, yaitu $25 \mathrm{~mm}$ dari ujung nozzle. Pada jarak $25 \mathrm{~mm}$ terlihat bahwa dengan perbedaan variasi lip thickness pada nozzle terpancung 16, 12, dan $8 \mathrm{~mm}$, menyebabkan perubahan temperatur. Semakin kecil lip thickness pada nozzle terpancung menyebabkan proses pencampuran antara bahan bakar dan udara semakin baik yang ditunjukkan dengan meningkatnya nilai temperatur pada titik tinjau yang sama. Selain itu dari grafik juga terlihat bahwa temperatur tertinggi berada pada dearah tengah api yaitu pada titik tinjau $0 \mathrm{~mm}$ arah horizontal, sedangkan pada titik tinjau -10 dan 10 $\mathrm{mm}$ temperatur yang dihasilkan cenderung lebih rendah. Hal ini mengindikasikan bahwa aliran bahan bakar masih terpusat pada bagian tengah nozzle, sedangkan pada bagian sisi proses pencampuran antara bahan bakar dan udara sebagian besar terjadi secara difusi.

Pada nozzle $4 \mathrm{~mm}$ dan $0 \mathrm{~mm}$ dapat dilihat bahwa profil temperatur cenderung lebih tinggi pada bagian sisi yaitu titik tinjau -10 dan $10 \mathrm{~mm}$ daripada bagian tengah atau titik tinjau $0 \mathrm{~mm}$. Hal ini mengindikasikan bahwa zona resirkulasi aliran sudah mulai terbentuk pada ujung nozzle. Zona resirkulasi aliran timbul akibat pemecahan laju aliran yang menyebabkan fokus aliran bahan bakar tidak hanya terpusat pada bagian tengah nozzle. Selain itu zona resirkulasi aliran menyebabkan timbulnya pusaran dan aliran balik di sekitar ujung nozzle yang berfungsi sebagai pengaduk dalam proses pencampuran antara bahan bakar dan udara sehingga proses pencampuran reaktan pada bagian sisi nozzle tidak hanya terjadi secara difusi tetapi juga karena adanya mixing aliran. Mixing aliran dapat menyempurnakan pembakaran karena membuat campuran bahan bakar dan udara lebih homogen, sehingga temperatur pembakaran yang dihasilkan lebih tinggi

Pada jarak vertikal $50 \mathrm{~mm}$ secara umum profil temperatur dari masing- masing nozzle pengujian tidak jauh berbeda dengan profil pada titik tinjau 25 $\mathrm{mm}$ yaitu dengan semakin kecilnya lip thickness pada nozzle terpancung menyebabkan temperatur pada semua titik tinjau semakin tinggi. Yang menarik di sini adalah pada tiga titik tinjau horizontal, profil temperatur pada hampir semua nozzle pengujian melandai. Ini menunjukkan bahwa pada titik tinjau vertikal $50 \mathrm{~mm}$, pembakaran bisa dikatakan hampir merata pada semua titik tinjau horizontal. Dengan kata lain secara umum zona resirkulasi aliran sudah terbentuk pada semua nozzle pengujian. Semakin kecil lip thickness pada nozzle terpancung menyebabkan semakin besar zona resirkulasi aliran yang menyebabkan pembakaran semakin sempurna dan merata sehingga temperatur api yang dihasilkan semakin tinggi. Secara khusus pada kasus nozzle terpancung dengan lip thickness $0 \mathrm{~mm}$, temperatur pada bagian tepi api yaitu titik tinjau -10 dan $10 \mathrm{~mm}$ lebih tinggi daripada bagian tengah atau $0 \mathrm{~mm}$. Hal ini terjadi akibat intensitas turbulensi dan pusaran aliran yang terlalu tinggi sehingga sebagian besar bahan bakar yang keluar nozzle terpecah ke bagian sisi nozzle, akibatnya pada bagian pusat nozzle atau titik tinjau $0 \mathrm{~mm}$ terjadi kekurangan bahan bakar sehingga temperatur yang dihasilkan lebih rendah

Gambar 9 menunjukkan distribusi temperatur pada jarak vertikal $100 \mathrm{~mm}$. Pada jarak ini secara umum tetap terlihat bahwa semakin kecil lip thickness pada nozzle terpancung menyebabkan terperatur yang dihasilkan juga semakin tinggi. Temperatur tertinggi terletak pada jarak -10 dan $10 \mathrm{~mm}$ untuk nozzle terpancung dengan lip thickness $0 \mathrm{~mm}$. Pada nozzle 0 $\mathrm{mm}$ juga terlihat bahwa penyebaran temperatur pada semua titik tinjau hampir merata, terlihat pada profil temperatur yang semakin landai. Untuk nozzle yang lain temperatur tertinggi untuk masing-masing nozzle 
berada pada titik tinjau horizontal $0 \mathrm{~mm}$ atau daerah tengah api. Pada nozzle terpancung dengan lip thickness $4 \mathrm{~mm}$ temperatur landai, artinya daerah yang mempunyai temperatur seimbang pada hampir semua titik pengukuran sedangkan temperatur terendah dihasilkan oleh nozzle terpancung dengan lip thickness $16 \mathrm{~mm}$ pada jarak horizontal -10 dan 10 $\mathrm{mm}$.

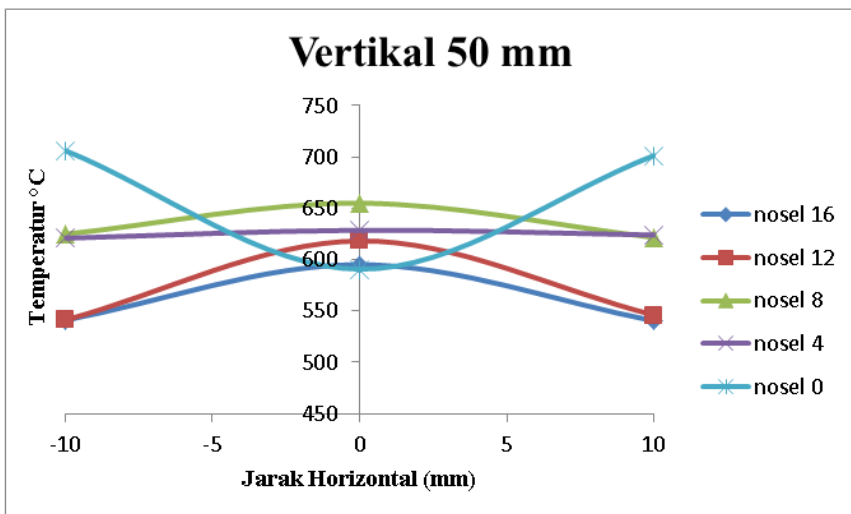

Gambar 8. Grafik distribusi temperatur api pada titik tinjau vertikal $50 \mathrm{~mm}$ dengan variasi lip thickness pada nozzle terpancung

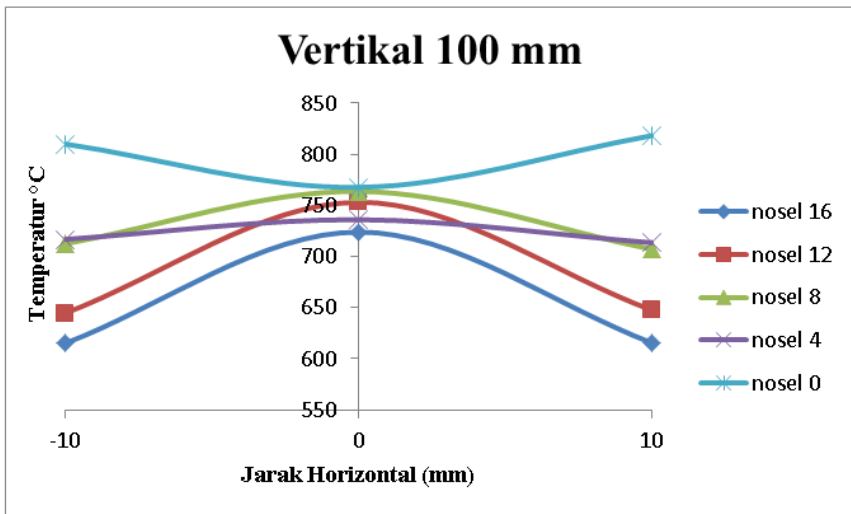

Gambar 9. Grafik distribusi temperatur api pada titik tinjau vertikal $100 \mathrm{~mm}$ dengan variasi lip thickness pada nozzle terpancung

\section{pada nozzle terpancung}

Pada jarak vertikal $200 \mathrm{~mm}$, secara umum temperatur tertinggi untuk semua variasi lip thickness nozzle terpancung berada pada jarak horizontal $0 \mathrm{~mm}$ atau tengah api. Temperatur terendah ada pada nozzle terpancung dengan lip thickness $12 \mathrm{~mm}$ yang terjadi hampir di semua titik pengukuran horizontal. Dari gambar 10 juga terlihat bahwa temperatur tertinggi dimiliki oleh nozzle terpancung dengan lip thickness $8 \mathrm{~mm}$ yang pola dan nilainya cenderung identik atau berhimpit dengan nozzle terpancung dengan lip thickness $4 \mathrm{~mm}$, kemudian diikuti oleh nozzle terpancung dengan lip thickness $0 \mathrm{~mm}, 16 \mathrm{~mm}$ dan terakhir $12 \mathrm{~mm}$. Pada ketinggian ini temperatur puncak nozzle $16 \mathrm{~mm}$ lebih tinggi daripada nozzle 12 $\mathrm{mm}$. Kemungkinan pada titik ini merupakan reaksi puncak pembakaran, karena pada nozzle $16 \mathrm{~mm}$ arah aliran bahan bakar cenderung terfokus pada bagian tengah api, sehingga pada ketinggian ini masih terdapat banyak bahan bakar yang belum terbakar. Rata-rata pada jarak ini didapatkan temperatur tertinggi dari setiap nozzle karena daerah ketinggian tersebut reaksi pembakaran semakin baik akibat reaktan telah mengalami pemanasan awal pada daerah dibawahnya. Akan tetapi khusus pada nozzle terpancung dengan lip thickness $0 \mathrm{~mm}$ justru mengalami penurunan temperatur jika dibandingkan dengan temperatur pada jarak vertikal $100 \mathrm{~mm}$. Hal ini terjadi karena pada nozzle $0 \mathrm{~mm}$, kemungkinan seluruh bahan bakar sudah terbakar habis sebelum mencapai jarak 200 mm, sehingga pada titik tinjau tersebut yang terukur hanya sisa panas dari reaksi pembakaran sebelumnya.

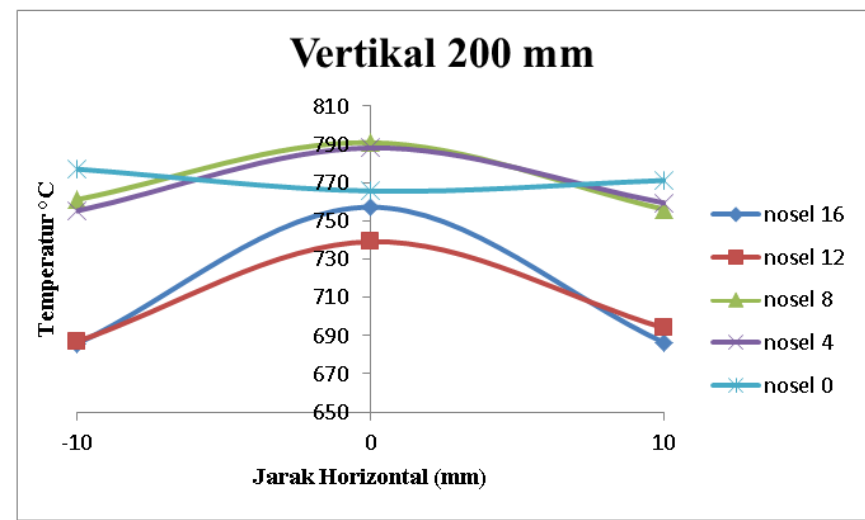

Gambar 10. Grafik distribusi temperatur api pada titik tinjau vertikal $200 \mathrm{~mm}$ dengan variasi lip thickness

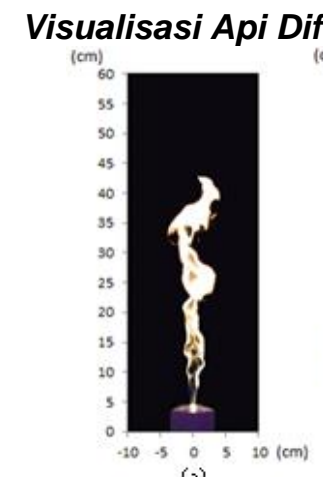

(a)

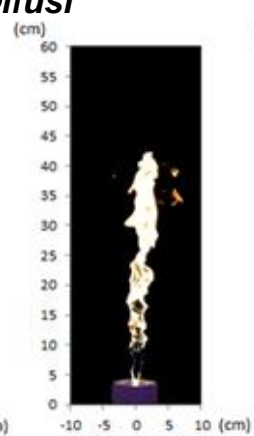

(b)

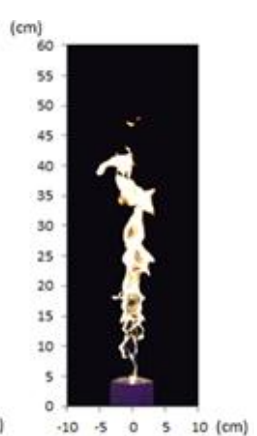

(c)

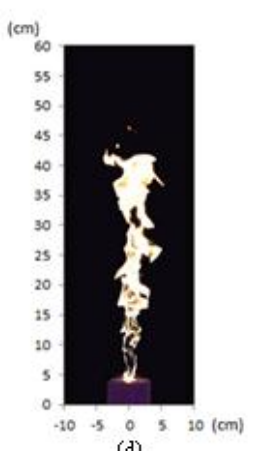

(d)

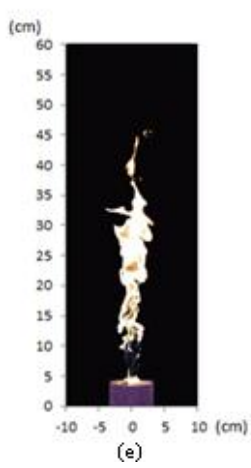

(e)
Gambar 11. Visualisasi api direct photograph dengan variasi lip thickness pada nozzle terpancung. 
Gambar 11 merupakan visualisasi api secara direct photograph dengan variasi lip thickness nozzle terpancung pada kondisi kecepatan udara dan bahan bakar yang sama yaitu $\mathrm{V}_{\mathrm{u}}=3,56 \mathrm{~m} / \mathrm{s}$ dan $\mathrm{V}_{\mathrm{b}}=11,8$ $\mathrm{m} / \mathrm{s}$. Dari gambar 11 (a) terlihat bahwa dengan penggunaan lip thickness nozzle terpancung $16 \mathrm{~mm}$, pangkal api terlihat kecil dan semakin melebar keatas seiring bertambahnya tinggi api. Warna pangkal api juga masih didominasi warna kuning yang menunjukkan proses pencampuran bahan bakar dan udara sebagian besar masih melalui proses difusi. Pada gambar 11 (b) mulai terlihat efek perubahan lip thickness pada nozzle terpancung. Dimana dengan penggunaan lip thickness $12 \mathrm{~mm}$ nyala pangkal api menjadi sedikit lebih lebar dan semakin terlihat warna biru. Hal ini menunjukkan bahwa semakin kecil lip thickness pada nozzle terpancung menyebabkan meningkatnya intensitas turbulensi aliran. Zona resirkulasi aliran semakin membesar seiring dengan mengecilnya lip thickness pada nozzle terpancung. Kemudian berturut-turut dari gambar 11 (c), (d), dan (e) semakin jelas dimana nyala pangkal api terlihat semakin melebar dan semakin biru yang menunjukkan proses pembakaran semakin sempurna. Secara keseluruhan dengan penggunaan variasi lip thickness pada nozzle terpancung pada kecepatan udara dan bahan bakar yang sama, tinggi api dapat dikatakan tidak mengalami perubahan panjang yang signifikan dan warna api dari semua variasi lip thickness nozzle terpancung sebagian besar masih didominasi warna kuning yang disebabkan oleh reaksi pembentukan jelaga yang menjadi ciri khas dari pembakaran difusi.

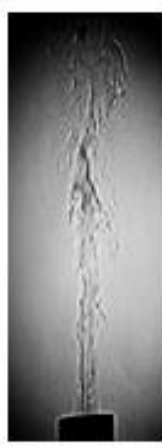

(a)

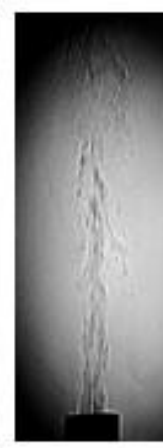

(b)

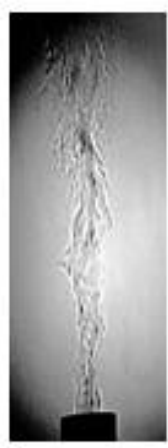

(c)

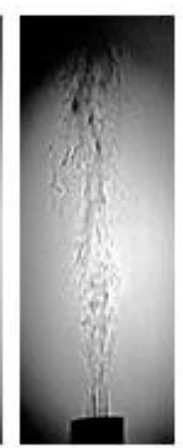

(d)

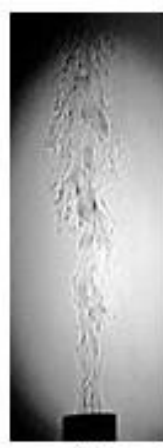

(e)
Gambar 12. Visualisasi api shadowgraph dengan variasi lip thickness pada nozzle terpancung.

Hal ini diperkuat dengan visualisasi shadowgraph pada gambar 12 (a) dimana terlihat bahwa aliran bahan bakar yang keluar nozzle mengalir panjang lurus keatas tanpa gangguan dan berangsurangsur bercampur dengan udara seiring bertambahnya tinggi api atau berkurangnya tekanan keluar nozzle. Dapat dilihat bahwa pada penggunaan nozzle terpancung dengan lip thickness $16 \mathrm{~mm}$, terjadinya pemecahan laju aliran bahan bakar yang menyebabkan terbentuknya zona resirkulasi aliran masih sangat kecil, akibatnya aliran bahan bakar masih terfokus pada bagian tengah api, sehingga pola aliran bahan bakar tidak hanya terfokus pada bagian tengah api. Kemudian pada visualisasi shadowgraph gambar 12 (b) panjang aliran bahan bakar pada bagian tengah api mengalami penurunan jika dibandingkan gambar 12 (a). Hal ini terjadi akibat adanya perluasan zona resirkulasi aliran, sehingga proses pencampuran antara bahan bakar dan udara lebih baik. Selanjutnya berturut-turut dari gambar 12 (c), (d), dan (e) semakin memperkuat dugaan bahwa semakin kecil lip thickness pada nozzle terpancung menyebabkan zona resirkulasi aliran semakin membesar yang ditandai dengan semakin kecilnya panjang aliran bahan bakar pada bagian tengah api akibat pemecahan laju aliran dan meningkatnya intensitas turbulensi aliran reaktan, sehingga proses mixing reaktan semakin baik dan pembakaran semakin sempurna.

\section{KESIMPULAN}

Setelah dilakukan penelitian dapat ditarik kesimpulan:

1. Semakin kecil lip thickness pada nozzle terpancung mengakibatkan kestabilan dan nyala api difusi concentric jet flow semakin meningkat. Kestabilan api difusi concentric jet flow terbesar diperoleh pada penggunaan nozzle terpancung dengan lip thickness $4 \mathrm{~mm}$.

2. Temperatur api difusi concentric jet flow tinggi dengan semakin kecilnya lip thickness pada nozzle terpancung.

3. Temperatur tertinggi diperoleh pada nozzle terpancung dengan lip thickness $0 \mathrm{~mm}$ sebesar $818,27^{\circ} \mathrm{C}$ dan berada pada bagian tepi api, yakni pada jarak horizontal $10 \mathrm{~mm}$ serta pada jarak vertikal $100 \mathrm{~mm}$.

4. Semakin tinggi kecepatan udara akan membuat nyala api semakin pendek dan melebar. Memperkecil lip thickness pada nozzle terpancung membuat daerah kestabilan semakin luas karena membuat proses mixing reaktan semakin baik sehingga campuran bahan bakar dan udara semakin homogen.

\section{DAFTAR PUSTAKA}

[1] Coats, C. M., \& Zhao, H. 1988. Transition and Stability of Turbulent Jet Diffusion Flames. Twenty-Second Symposium (International) on Combustion- The Combustion Institute, 22, 685692.

[2] Takahashi, F., \& Schmoll, W. J. 1990. Lifting criteria of jet diffusion flames. Symposium (International) on Combustion, 23(1), 677-683.

[3] Rohmat, T.A., Yoshihashi, T., Obara, T., \& Ohyagi, S. 1999. An Experimental Study of Turbulent Diffusion Flames Established on a Porous Plate Behind a Backward-Facing Step. Proceedings of the 5th ASME/JSME Joint Thermal Engineering Conference, California.

[4] Miake-lye, R. C., \& Hammer, J. A. 1988. Jet Flames: a Stability Criterion Based on the Jet Large-Scale Structure. Twentieth Symposium 
(international) on Combustion. The Combustion Institute, 817-824.

[5] Soenoko, R., 2010. The Effect of a Flame Holder Shape Modification Toward the Diffusion Flame Stability Zone Shift, 8(3), 339-344.

[6] Akbar L., 2013. Pengaruh Sudut Cetral Fuel Tube Terhadap Kestabilan dan Temperatur Nyala Api Difusi Double Concentric Jet Flow. Vol.III: 122.04.XII.592.
[7] Widodo, A. S., 2004, Pengaruh Posisi dan Sudut Kemiringan Swirl Terhadap Kestabilan Pancaran Api Difusi Double Concentric, Malang: Jurnal Ilmu-ilmu Teknik Vol. 16 No.2, Lembaga Penelitian Universitas Brawijaya. 